\title{
COMIDA TRADICIONAL XAVANTE
}

\author{
URÉBÉTÉ ${ }^{1}$, Edgar Tsere'õmorãté \\ Universidade Federal de Goiás
}

\section{RESUMO}

Pesquisei sobre o tema da comida tradicional do povo A'uwẽ, para a comunidade A'uwẽ recordar a sua comida natural e valorizá-la.

Palavras-chave: Comida tradicional. Valorização. Cultura A'uwẽ - Xavante.

\section{ABSTRACT}

I researched the theme of the traditional food of the A'uwẽ people, for the A'uwẽ community to remember their natural food and value it.

Key words: Traditional food. Appreciation. A'uwẽ - Xavante Culture.

\section{INTRODUÇÃO}

Quando fiz a pesquisa "Comida tradicional do povo A'uwẽ", da minha comunidade dentro da aldeia São Marcos, andava em cada casa de ancião para perguntar sobre o tema. Mas, atualmente, o ancião A'uwẽ, na hora da pesquisa, faz cobrança sobre a pesquisa da fala dele, mas não pede o recurso, pede o que ele gosta de comer. Tem quatro principais coisas que o ancião pede: café, carne, frango, peixe.

Pesquisei sobre o tema da comida tradicional do povo A'uwẽ para a comunidade A'uwẽ recordar a sua comida natural. É para a valorização da comida tradicional A'uwẽ e aprender como retira a comida tradicional A'uwẽ. É reconhecer tipos de comida naturais, sua utilidade e preservar. A comunidade A'uwẽ deve aprender a história da comida natural. O A'uwẽ deve contribuir com essa história da comida tradicional A'uwẽ e pesquisar junto com o ancião, buscar no mato e no cerrado, reunir a comunidade A'uwẽ para os (as) anciões (ãs) fazerem palestra sobre cada seu conhecimento sobre a comida tradicional A'uwẽ.

Meu trabalho se justifica pela importância de se pedir para comunidade buscar a comida tradicional A'uwẽ no mato e no cerrado,

1 Rede UFG/UFT/UFMA. Professor de Educação Básica. 
junto com os (as) anciões (ãs), alertar a comunidade A'uwẽ sobre a comida natural, pedir para a comunidade fazer pesquisa junto com os (as) anciões (ãs) para fazer plantações dentro da aldeia A'uwẽ. Para isso, esse trabalho foi elaborado junto com os anciões e as anciãs, para participação da discussão do conteúdo sobre a comida tradicional A'uwẽ, no mato e no cerrado, e avaliação prática de fazer a comida tradicional A'uwẽ.

\section{A comida tradicional A'uwẽ}

Antigamente a comida tradicional do povo A'uwẽ era totalmente viva e natural, porque antes não tinha nada das coisas do não índio. Antes o A'uwẽ vivia sozinho dentro do seu território, e não sabia falar outros idiomas. Porém, o A'uwẽ comia suas próprias comidas tradicionais e naturais. Quando os homens buscavam os alimentos naturais no mato e no cerrado, eles traziam para casa e para seus familiares. Quando traziam para a aldeia, a mulher fazia a comida para suas famílias dentro da casa. A comida A'uwẽ era muito boa, sem substâncias químicas e não tinha gordura. Era muito natural.

Atualmente, os jovens A'uwẽ não se interessam para buscar a sua própria comida no mato e no cerrado. Preferem a comida industrializada que buscam na cidade e trazem para a aldeia. Comem e não recordam a sua própria comida natural.

A alimentação dos A'uwẽ sofreu grandes alterações após o contato com os waradzu, não índio, ocorrido há 50 anos. Antes, havia o consumo regular de carne de caça, do milho, do feijão A'uwẽ e de frutas do cerrado. A mudança mais evidente foi a troca do milho e do feijão A'uwẽ, importantes fontes de proteínas e de ferro, pelo arroz branco.

Hoje o cereal, introduzido pelo não índio, é o principal alimento do povo A'uwẽ. Uma das razões é a facilidade de plantio e colheita. Hoje, é comum ver crianças e adultos comerem apenas arroz branco nas refeições. No dia a dia, a população A'uwẽ se alimenta cada vez mais de biscoitos, açúcar e sal, refrigerantes, macarrão, farinhas refinadas e salgadinhos.

Antes tinha o alimento do povo A'uwẽ, como a produção da receita tradicional do bolo de milho A'uwẽ, feito na brasa, tsada 'ré, o tsada 'ré do jeito como as anciãs ensinaram. Primeiramente, o milho era pilado e peneirado, transformando-se em uma farinha ou em pó. 
As indígenas adicionavam água e faziam uma massa, colocando-a nas folhas de bananeira-brava, e cobriam com essa folha em formato circular.

Durante a montagem do bolo tsada'ré, as anciãs quebravam os cupinzeiros, jogando-os em cima do fogo com madeira. A terra de cupinzeiro tem propriedades que permitem a absorção de uma grande quantidade de calor, se carbonizar o alimento. Após a montagem do bolo tsada 'ré nas folhas de bananeira, ele era colocado sobre o fogo e a terra dos cupinzeiros. Deste modo, cozinhava por aproximadamente três horas.

\section{CONSIDERAÇÕES FINAIS}

É preciso voltar como era a alimentação do povo A'uwẽ antes do contato com os brancos, porque os A'uwẽ estão ficando mais doentes depois que foram inseridos alimentos industrializados, como açúcar, refrigerante, salgadinho e muito mais. Os anciões da aldeia contaram sobre como era alimentação dos índios A'uwẽ antes do contato com os homens brancos. Disseram que hoje em dia os índios estão adoecendo mais conforme trocam suas comidas tradicionais pela alimentação industrializada.

Esta mudança na alimentação, entre outros fatores, causa, nos adultos, doenças que eram inexistentes antes do contato, como pressão alta, doenças do coração e diabetes. Essas doenças, antigamente, não tinham, porque os A'uwẽ só se alimentavam da sua comida natural. Por causa da comida natural os A'uwẽ são fortes.

Por isso, nós A'uwẽ temos que voltar para a nossa comida natural, porque hoje em dia, tem muitos jovens, tanto homens quanto mulheres, que têm obesidade por causa da comida industrializada, mas é muito difícil para voltarmos à nossa comida natural. Enquanto isso, temos que buscar o conhecimento dos anciões para que os jovens se esforcem na ideia, para trabalharem e roçarem, fazerem plantações da comida natural, plantação de milho A'uwẽ, mo'õni, ubdi, mo'õnihoi'ré, patede, póné'ê're, enfim, essas frutas que vivem embaixo da terra e no mato.

Atualmente, existem poucas dessas frutas e a comida natural. A comida industrializada é maior do que antes. Enquanto isso, entre os A'uwẽ acontecem doenças cedo por causa da comida, que tem muitas substâncias químicas, e muita gordura e doce. 
